\title{
LINGUÍSTICA APLICADA E FORMAÇÃO DE PROFESSORES DE LÍNGUAS: CONCEITOS E TRAMITAÇÕES
}

\author{
SILVIO NUNES DA SILVA JÚNIOR ${ }^{1}$
}

Programa de Pós-Graduação em Letras e Linguística, Universidade Federal de Alagoas Faculdade de Letras, Avenida Lourival Melo Mota, Tabuleiro dos Martins 57083410, Maceió, AL - Brasil

junnyornunes@hotmail.com

\begin{abstract}
Resumo. O presente estudo busca refletir teoricamente sobre a preocupação em se empregar estudos no campo da linguística aplicada (LA) direcionados com maior ênfase à formação de professores de línguas. Diante da discussão teórica expandida sobre o papel do linguista aplicado e algumas das abordagens contemporâneas sobre a formação de professores no campo da LA, concluímos que a educação linguística vem remeter a defesa de um ensino pautado na linguagem em sentido macro; a LA transgressiva traz ricas contribuições com os temas basilares para o debate com base no estudo da linguagem em sala de aula; e os estudos sobre letramento surgem como medida de conscientização da comunidade docente acerca de seus papeis enquanto aprendizes quando exercem o trabalho de agentes nas práticas de letramento.
\end{abstract}

Palavras-chave: linguista aplicado; educação linguística; práticas de letramento.

\begin{abstract}
The present study seeks to reflect theoretically on a concern in rehearsing studies in the field of applied linguistics (LA) directed with more training in language teacher training. Faced with the expanded theoretical discussion on the role of applied language and some of the contemporary approaches to teacher training in Latin America, we conclude that a linguistic education comes to refer to a defense of a language-oriented teaching in the macro sense; The transgressive LA brings rich contributions with the basic themes to the debate based on the study of language in the classroom; And studies on creating a text as a measure of community awareness.

Keywords: applied linguist; linguistic education; literacy practices.
\end{abstract}

\footnotetext{
${ }^{1}$ Mestrando em Linguística pelo Programa de Pós-Graduação em Letras e Linguística da Universidade Federal de Alagoas (PPGLL/UFAL) e Pós-Graduando da Especialização em Linguagens e Educação a Distância na Universidade Federal de Santa Catarina (UFSC).
} 


\section{Introdução}

Do seu surgimento no cenário científico ao seu status atual como componente das ciências sociais ou, por outro lado, uma subárea da linguística, a linguística aplicada (doravante LA) provoca, a cada estudo publicado, a aparição de muitos questionamentos sobre quais são os seus objetos de pesquisa, quais as suas finalidades na linguística ou nas ciências sociais, e qual seria, após isso tudo, o papel do linguista aplicado como pesquisador que se dedica a expandir a LA no âmbito acadêmico. A única constatação até então relativamente estável gira em torno dos três principais cenários de atuação do linguista aplicado, sendo estes: o ensino-aprendizagem de línguas (maternas ou estrangeiras), a formação de professores de línguas e, há poucos anos, os gêneros do discurso e outros estudos pautados em perspectiva dialógica.

Nessa perspectiva, Bianca Falabella Fabrício (2006, p. 48), em Linguística aplicada como espaço de "desaprendizagem": redescrições em curso, aponta que a LA se encontra num estado de revisão de bases epistemológicas, visando à compreensão:

- de que, se a linguagem é uma prática social, ao estudarmos a linguagem estamos estudando a sociedade e a cultura das quais ela é parte constituinte e constitutiva;

- de que nossas práticas discursivas não são neutras, e envolvem escolhas (intencionais ou não) ideológicas e políticas, atravessadas por relações de poder, que provocam diferentes efeitos no mundo social;

- de que há na contemporaneidade uma multiplicidade de sistemas semióticos em jogo no processo de construção de sentidos.

Considerando esse período importante de observar as finalidades e possíveis implicações que os estudos da LA podem desenvolver, pode-se destacar que a heterogeneidade concernente aos âmbitos de pesquisa em LA permanece nas três justificativas apresentadas por Fabrício (2006). Dessa forma, seria impossível tratar de LA sem pensar na sociedade pós-moderna e suas intersecções, bem como seria impossível tratar das relações entre linguagem e sociedade, o que implica no ensino, sem mencionar a LA, isto porque abordagens como a de LA mestiça buscam "criar intelegibilidade sobre problemas sociais em que a linguagem tem um papel central" (MOITA LOPES, 2006, p. 14).

Tida essa breve discussão sobre como a LA vem se alavancando ao passar dos anos e situando os seus pesquisadores num contexto cada vez mais amplo, o presente estudo vem focalizar na formação de professores de línguas, apontando como essa questão vem sendo trabalhada em diferentes abordagens no campo da LA. Nessa perspectiva, denominamos, para a discussão, três temas atuais no campo da LA, escolhidos com base em algumas leituras de textos do referido campo, estes sendo: a educação linguística, a LA transgressiva e o letramento do professor. Reconhecemos a importância de outras tendências da LA, como a discursiva. No entanto, o trabalho, em sua estrutura, não comportaria tantas abordagens.

Após essas considerações iniciais, os demais tópicos, além das considerações finais, vêm discutir: o trabalho do linguista aplicado, por meio de contextualizações teóricas como as de Moita Lopes (2006), Cavalcanti (1986), Kleiman (1998), Thiollent (1988), Zozzoli (2006) e outros; e a formação de professores de línguas em diferentes 
abordagens, como: a educação linguística ( $c f$. CAVALCANTI, 2013; VASCONCELOS, 2009; VIAN JR, 2011; SILVA JÚNIOR, 2017), a LA transgressiva ( $c f$. PENNYCOOK; 2006; WIDDOWSON, 2001) e o letramento do professor ( $c f$. STREET, 1984, 2014, 1984, 2006, 2013; KLEIMAN, 1995, 2008, 2010; SANTOS, 2004; SOARES, 1998; ROJO, 2009; SILVA, 2009; ROJO, 2013; LOPES, 2006).

\section{O trabalho do linguista aplicado: a finalidade do campo de atuação e apontamentos sobre o foco de pesquisas}

Há muitos anos vem sendo discutido internacionalmente qual seria realmente o campo e a perspectiva de estudo do linguista aplicado. Inicialmente, podemos mencionar que o papel desse pesquisador é o de desenvolver estudos no campo da LA, no intuito de, dessa forma, contribuir para o progresso da mesma. No entanto, outra questão abordada constantemente seria qual é o objetivo da LA e se esse campo realmente pertence à linguística que conhecemos nos discursos que permeiam os cursos de graduação e pósgraduação (lato sensu e stricto sensu) em Letras, em instituições públicas e privadas no Brasil e outros países.

Uma vez sendo o nosso maior objetivo discutir sobre teorias desenvolvidas no território nacional, o primeiro teórico que merece destaque nessa discussão é Moita Lopes, autor de obras de grande relevância na LA, sendo o principal responsável pela repercussão de seu nome no Brasil e no mundo, a "Oficina de Linguística Aplicada", em 1996, seguindo com obras de sua autoria e/ou organização, como por exemplo: "Identidades fragmentadas: a construção discursiva de raça, gênero e sexualidade em sala de aula" (2002), "Por uma linguística aplicada indisciplinar" (2006); e, "Linguística Aplicada na modernidade recente" (2013). Fora esse autor, outros teóricos também se consagraram nesse campo, como: Kleiman (1998), Cavalcanti (1986) e Rojo (2006), isso principalmente por dedicarem alguns de seus estudos para desmistificar discursos diversos sobre a finalidade de estudo da LA, a qual ainda era vista como uma aplicação da linguística teórica aos contextos de ensino-aprendizagem de línguas.

Sobre esses discursos, Moita Lopes (2006) assinala que "a LA já fez a crítica a essa formulação reducionista e unidirecional de que as teorias linguísticas forneceriam a solução para os problemas relativos à linguagem com que se defrontam professores e alunos em sala de aula" (p. 17). Assim, já se pode perceber um desacordo entre as teorias linguísticas com a LA que, pelo Conselho Nacional de Pesquisa e Desenvolvimento Científico e Tecnológico (CNPq), por intermédio da Plataforma Lattes, ainda vem sendo tida como uma subárea da linguística, onde aparece a psicolinguística, a sociolinguística, a análise do discurso etc.

Nessa perspectiva, o mesmo autor ainda ressalta o seguinte questionamento importante e seu ponto de vista sobre o mesmo:

como é possível pensar que teorias linguísticas, independentemente das convicções dos teóricos, poderiam apresentar respostas para a problemática do ensinar/aprender línguas em sala de aula? Uma teoria linguística pode fornecer uma descrição mais acurada de um aspecto 
linguístico do que outra, mas ser completamente ineficiente do ponto de vista do processo de ensinar/aprender línguas (op. cit., p. 18).

Nesse sentido, ao pensar em realizar interfaces entre as teorias linguísticas com o processo de ensino-aprendizagem, os olhares de toda e qualquer pesquisa vão apontar para uma reformulação do que entendemos por ensino de línguas, ou seja, não seria possível aplicar teorias que divergem em tantos pontos para a prática pedagógica em contextos de ensino-aprendizagem.

De serem necessárias para a formação de professores, tanto de língua materna como de língua estrangeira, as teorias linguísticas podem contribuir para o conhecimento linguístico do professor e, por consequência, leva-o a desenvolver uma concepção de linguagem que se adeque ao ensino da língua em que se esteja ensinando. No entanto, a educação escolar brasileira ou, mais precisamente, o ensino de línguas e outros componentes curriculares, seguem as diretrizes apontadas em seus respectivos parâmetros curriculares $^{2}$. Por essa razão, as teorias linguísticas se tornam bases apenas para a educação linguística do professor e estariam longe de solucionar e/ou aprimorar problemas de linguagem em sala de aula.

Isso poderia se justificar, ainda, por saber que a "LA no Brasil é quase totalmente de natureza qualitativa, com preocupações com o idiossincrático, o particular e o situado" (MOITA LOPES, 2012 apud MOITA LOPES, 2013, p. 17). Dessa forma, estabelecer uma visão de LA como aplicação da linguística seria pensar uma prática de ensinoaprendizagem vinculada a pressupostos quantitativos, isto é, preocupados com dados de quantificação, sem se importar com a qualidade do processo.

É válido lembrar, em se tratando dos problemas de linguagem estudados na LA, que "não se trata de qualquer problema - definido teoricamente -, mas de problemas com relevância social suficiente para exigirem respostas teóricas que tragam ganho a práticas sociais de seus participantes" (ROJO, 2006, p. 258). Com isso, por mais que existam problemas de linguagem, as suas soluções devem partir de aplicações específicas ( $c f$. MOITA LOPES, 1998).

A LA, como assinala Rojo (2006), é um "campo de estudos e pesquisas como resultado entre a privação sofrida e a levitação teórica desejada" (p. 253). Em outras palavras, ela corresponde à unção entre os problemas de linguagem com as variadas possibilidades de resolução através da reflexão e da crítica. Ela é uma área descentralizada ${ }^{3}$, podendo ser aplicada em diversas situações e contextos.

\footnotetext{
${ }^{2}$ Os Parâmetros Curriculares Nacionais para o ensino de língua portuguesa apresentam uma visão de linguagem altamente veiculada à concepção sociointeracionista de linguagem, bem como ao dialogismo trazido pelos estudos do chamado círculo de Bakhtin. Essa conclusão parte do seguinte trecho: "a variação é constitutiva das línguas humanas, ocorrendo em todos os níveis. Ela sempre existiu e sempre existirá, independentemente de qualquer ação normativa. Assim, quando se fala em "língua portuguesa" está se falando de uma unidade que se constitui de muitas variedades, [...] A imagem de uma língua única, mas próxima da modalidade escrita da linguagem, subjacente ás prescrições normativas da gramática escolar, dos manuais e mesmo dos programas de difusão da mídia sobre "o que se deve e o que não se deve falar e escrever", não se sustenta na análise empírica dos usos da língua” (BRASIL, 1998, p. 29).

${ }^{3}$ O termo "descentralização", como explica Hall (2003), corresponde a um processo de transformação ou fragmentação de identidade, o que ocorre por meio das experiências socioculturais de cada indivíduo.
} 
Rojo (2006), na mesma perspectiva, ainda lembra que a linguagem é constituída por jogos, ou seja, o objeto de estudo da LA situa-se nesses jogos presentes em unidades de análise; porém, a análise feita pelo linguista aplicado não se limita aos seus conhecimentos empíricos, mas, em pesquisas teóricas e práticas empregadas na linguística e em outras áreas de conhecimento.

Vê-se, então, que a LA se distancia cada vez mais da linguística teórica, e, com o passar dos anos, chega a ser mais próxima dos Estudos Culturais ${ }^{4}$ e das Ciências Sociais, pelo seu caráter transgressivo e crítico, oriundo da necessidade de se problematizar a área e expandi-la ( $c f$. MOITA LOPES, 2013; PENNYCOOK, 2006). Em seu cruzamento com os estudos culturais, a LA vem sendo cenário para muitos estudos relacionados aos processos identitários, de forma a preocupar-se com o estabelecimento de crenças e valores em contextos de linguagem em uso.

Um dos estudos que se destacam nessa linha de pensamento é o de Souto Maior (2009), onde se detém olhares sobre as constituições de ethos $^{5}$ e os discursos envolventes em contexto de ensino-aprendizagem de língua portuguesa. A autora aponta na pesquisa que o sujeito, em situações de aprendizagem, constrói imagens identitárias que apontam as construções de identidades sociais, culturais, políticas, linguísticas etc., isso feito com base na pesquisa-ação.

A pesquisa-ação, atualmente, vem sendo o tipo de pesquisa mais empregado na LA, uma vez que traz consigo a possibilidade de intervir nos contextos de linguagem em que existem problemas ou aspectos que careçam de aprimoramento. Thiollent (1988, p. 16), aponta que:

\footnotetext{
- a pesquisa-ação é uma estratégia metodológica da pesquisa social na qual:

- há uma ampla e explícita interação entre pesquisadores e pessoas implicadas na situação investigada;

- desta interação resulta a ordem de prioridade dos problemas a serem pesquisados e das soluções a serem encaminhadas sob forma de ação concreta;

- o objeto de investigação não é constituído pelas pessoas e sim pela situação social e pelos problemas de diferentes naturezas encontrados nesta situação;

- o objetivo da pesquisa-ação consiste em resolver ou, pelo menos, em esclarecer os problemas da situação observada;
}

\footnotetext{
${ }^{4}$ Sobre os estudos culturais como fonte teórica para a linguística aplicada, concordamos com as considerações de Silva Júnior (2016a, 2016b), quando, parafraseando os estudos de Hall, aponta que: "Na pós-modernidade ou modernidade tardia alguns estudos culturais como os de Stuart Hall (2003) abrangem os estudos de/sobre identidade. Acredita-se, nesse contexto, que a construção das identidades culturais parte de uma descentralização de sujeito, porém, essa descentralização passa a ser vista como algo múltiplo, mas não homogêneo. Nesses estudos, a identidade do sujeito pode ser fragmentada por identidades diversas, construídas em todo o processo de formação" (2016a, p. 47).

5 "O ethos discursivo [...] divide-se em ethos mostrado e ethos dito. Esse último refere-se a uma evocação direta ou não da própria enunciação por parte do enunciador. Frases do tipo Eu, esse que vos fala ou metáforas e alusões indiretas evidenciam essa referência direta" (CRISTOVÃO, 2010, p. 22). No entanto, "a distinção entre ethos dito e mostrado se inscreve nos extremos de uma linha contínua, uma vez que é impossível definir uma fronteira nítida entre o "dito" sugerido e o puramente "mostrado" pela enunciação" (MAINGUENAU, 2008, p. 18).
} 
- há, durante o processo, um acompanhamento das decisões, das ações e de toda a atividade intencional dos atores da situação;

- a pesquisa não se limita a uma forma de ação (risco de ativismo): pretende-se aumentar o conhecimento dos pesquisadores e o conhecimento ou o "nível de consciência" das pessoas e grupos considerados.

Em se tratando do aprimoramento de contextos nos quais a linguagem atua, assim como uma pretensão de elevar o grau de conhecimento de pesquisadores da LA e a resolução de problemas nesses contextos, a pesquisa-ação não vem atuar como embasamento teórico e metodológico para se resolver e/ou aprimorar essas questões. $\mathrm{O}$ que se propõe na pesquisa-ação, segundo Zozzoli (2006), "é conhecer melhor as questões em jogo e refletir sobre encaminhamentos de ações" (p. 125).

Ainda nesse sentido, cabe ressaltar que nenhum tipo ou vertente de pesquisa utilizada na LA (etnografia, pesquisa interpretativista, estudo de caso etc.), pode ser fonte para meios de se desenvolver formas de resolver problemas de linguagem. Para tanto, isso dependerá da atuação do linguista aplicado em seu senso de pesquisador, ou seja, ao observar determinado contexto de uso, o pesquisador irá denominar o meio mais proveniente para se achar as referidas soluções ou propostas de aprimoramento.

Assim, o desenvolvimento de estudos no campo da LA, como os que foram brevemente explanados, possibilita que entendamos a atuação do linguista aplicado como a de um pesquisador do campo das ciências sociais. Sendo assim, a atuação do linguista aplicado não se limita as paredes da sala de aula, tanto que alguns estudos são realizados em âmbitos públicos e privados nos quais a linguagem atua através do processo de interação verbal e não verbal, como os hospitais, as delegacias e etc. Como última questão a ser lembrada no presente tópico, destaca-se que a LA abre cada vez mais espaço para ser abrangida no cenário científico, criando pressupostos teóricos, metodológicos e práticos para se estudar a linguagem em sentido macro e micro, nas mais variadas línguas vivas.

Com esses esclarecimentos, e, ainda, em inter-relação com as considerações de Rajagopalan (2006), quando o autor propõe 'repensar o papel da linguística aplicada', numa tentativa de "romper - na medida do possível - com a tradição, a fim de repensar o futuro do campo de forma livre e desimpedida" (p. 149), partimos, no tópico seguinte para algumas reflexões sobre a educação linguística, visto que essa perspectiva se direciona com bastante ênfase aos estudos da LA pautados nas questões de ensinoaprendizagem de línguas e formação docente, sendo a última o nosso foco no presente estudo.

\section{A formação de professores de línguas em diferentes abordagens na LA}

Esse tópico tem por finalidade apresentar como a LA contribui para a formação de professores de línguas por meio de diferentes abordagens teóricas que vêm sendo desenvolvidas por pesquisadores, como: a educação linguística, a transgressividade em pesquisas sobre formação de professores de línguas em LA e o letramento do professor; tendo, também, o intuito de apontar como os linguistas aplicados fazem o uso de outras 
linhas e áreas de pesquisa para complementar os seus estudos, e, por consequência, criar as suas propostas, ancorados nos diversos tipos de pesquisa qualitativa como na pesquisaação, na etnografia, estudos de caso e etc.

\title{
2.1. A educação linguística
}

A educação linguística começou a ser expandida no cenário científico através de estudos do campo da sociolinguística, tendo como seus principais representantes, estudiosos que se dedicam a realizar interfaces entre as teorias das variações linguísticas com o ensino, assim como: Bortoni Ricardo (2004, 2005), Bagno (2007) e outros. No entanto, a LA, da mesma forma, vem se dedicando a expandir reflexões sobre a educação linguística no intuito de defender a ideia de que exista uma educação linguística "que vá além do conhecimento sobre a língua alvo de ensino" (CAVALCANTI, 2013, p. 212).

Em LA, Vasconcelos (2009, p. 205) vem destacar que a educação linguística "põe em relevo a necessidade de que deve ser respeitado o saber linguístico próprio de cada um". Dessa forma, a principal finalidade de se refletir a educação linguística está voltada ao ensino-aprendizagem, com mais enfoque ao ensino de língua materna, uma vez que o aluno estará conhecendo com maior profundidade as particularidades de uma língua na qual ele já domina na fala. Quando se trata das línguas estrangeiras, a educação linguística já se direciona com maior impacto na formação de professores, pois na educação básica é inviável que se possa considerar o conhecimento linguístico ${ }^{6}$ do aluno em uma língua não dominada por ele.

\begin{abstract}
Nessa visão de educação linguística ampliada [...] (em) um curso de licenciatura nesse mundo de diáspora, imigração e migração, de mobilidade social cada vez mais emergente, precisaria enfatizar a formação de um professor posicionado, responsável, cidadão, ético, leitor crítico, com sensibilidade à diversidade e pluralidade cultural, social, linguística etc., sintonizado com seu tempo, seja em relação aos avanços tecnológicos seja em relação aos conflitos que causam qualquer tipo de sofrimento ou de rejeição a seus pares, lembrando que essas questões são cambiantes, fluidas assim como as construções identitárias nas salas de aula. (CAVALCANTI, 2011 apud CAVANCANTI, 2013, p. 212)
\end{abstract}

Considerando as transformações sociais que implicam com grande impacto na construção de identidades dos indivíduos, a sociedade global vem se dispersando de modelos relativamente prontos de vivência na tentativa de quebrar barreiras construídas pelos discursos definidos com o passar do tempo. Nesse sentido, a posição do professor no processo de escolarização deve acompanhar essas transformações e se enquadrar na chamada diáspora, bem como a mobilidade social, que o leva a ser cada vez mais crítico,

\footnotetext{
${ }^{6}$ Chamamos de conhecimento linguístico os processos de variação e mudança linguística que implicam no processo de ensino-aprendizagem, principalmente de língua portuguesa. Isto é, a forma com que os alunos fazem o uso das variações linguísticas utilizadas nas suas comunidades de fala. Bortoni-Ricardo (2004) defende, nessa perspectiva, uma pedagogia culturalmente sensível, onde os saberes dos alunos devem ser vistos de forma estratégica pelos professores, e estes devem incluir dois componentes na prática, a saber: a identificação da diferença e a conscientização da diferença.
} 
reflexivo e preocupado em relação a como a sociedade implica na educação e no ensino da linguagem em sala de aula.

Nessa linha de pensamento, refletir a educação linguística do professor de línguas requer mencionar o quanto os cursos de licenciatura plena são responsáveis para o estabelecimento de um ensino pautado na heterogeneidade linguística ${ }^{7}$, como se pode observar no primeiro rodapé do tópico que aborda o papel do linguista aplicado no presente estudo.

Vian Jr (2011, p. 67) aponta que:

O que temos observado em nossa prática é que os professores parecem não se preocupar com uma visão de linguagem, mas apenas com a língua como sistema e, a partir dessa perspectiva é que julgam que devem ser ensinadas tão-somente as estruturas linguísticas. Desprovidas de contexto, de uso, de significados, apenas a forma em si.

Retomando as primeiras considerações sobre LA tidas no início desse estudo, observamos que o conhecimento dos professores sobre a linguística teórica de alguma forma implica na sua prática, o que, para os teóricos da LA, é prejudicial; justamente por acarretar no seguimento de ensino de língua, fugindo da perspectiva ampla de linguagem ${ }^{8}$ que os PCN (1998) apresentam.

Tanto no ensino de língua materna como em língua estrangeira existe, em muitos casos, o seguimento de um sistema formal. Mesmo que a formação inicial em letras abarque um amontoado de teorias, a prática profissional de professores de línguas acaba seguindo a perspectiva tradicional de ensino, e isso ocorre por algumas causas referentes ao planejamento junto à coordenação pedagógica da escola, o livro didático e a orientação de professores que já estão na prática há mais tempo.

Nesse contexto, a noção de erro linguístico no ensino-aprendizagem de línguas, oriunda da sociolinguística, ganha destaque por assinalar que:

[...] o erro linguístico simplesmente não existe. O trabalho da escola, e não apenas do professor de português ${ }^{9}$, consiste em propiciar aos alunos um ambiente linguístico que lhes permita conviver com realizações linguísticas diferentes daquelas que eles já dominam, trazidas de suas redes sociais, abrindo-lhe possibilidades de expressão cada vez mais novas e mais ricas, surpreendentes, para a construção de sua autonomia nas práticas sociais de leitura e de escrita. Os eventos de letramento que

\footnotetext{
7 Corroboramos, com essa afirmação, com Silva Júnior (2017, p. 17-18), onde "o professor, como profissional oriundo dos cursos de licenciatura e da educação básica, precisa se enquadrar num contínuo processo de conscientização sobre a situação dos alunos e, por essa razão, ser culturalmente sensível (BORTONI-RICARDO, 2005) a ponto de estabelecer pontes e diálogos com os alunos de maneira que os mesmos possam sentir-se bem em fazer o uso da linguagem em sala de aula e, por consequência, aprender mutuamente.

${ }^{8}$ Ao apontarem a fala e a escrita como as modalidades de linguagem que precisam ser abordadas no processo de ensino-aprendizagem de língua, Koch e Elias (2011, p. 14) assinalam que "embora se utilizem do mesmo sistema linguístico, cada uma delas possui características próprias. Ou seja, a escrita não constitui mera transcrição da fala, como muitas vezes se pensa".

${ }^{9}$ Aqui se pode levar a mesma discussão para a língua estrangeira.
} 
as diversas disciplinas promovem, juntamente com toda a instituição escolar, é que irão ampliando competências nos alunos, tornando-os, cada vez mais, cidadãos críticos, autônomos. (CYRANKA; SCAFUTTO, 2011, p. 62-63, grifo das autoras)

O processo de adaptação de professores para com as teorias da LA, que, em seu apogeu, sempre tratou das práticas de ensino-aprendizagem de línguas tentando sempre implicar de alguma maneira no aprimoramento da prática de professores e da qualidade do ensino em detrimento de uma educação linguística nacional e até mesmo mundial, ainda percorrerá por alguns longos anos. Desse modo, é necessário que tanto as hierarquias educacionais como os professores atuantes em cursos de formação inicial e continuada busquem, na prática, meios para abranger cada vez mais a importância de uma educação linguística e, além disso, social, visto que a educação linguística do professor de línguas:

[...] não pode ser somente linguística, ela precisa ser sofisticadamente inter- e transdisciplinar, socialmente engajada, antropologicamente antenada, plural em seu foco, para incluir os estudos de letramento, os estudos sobre multilinguíssimo com as questões de intercompreensão e de práticas translíngues, os estudos sobre transculturalismo. (CAVALCANTI, 2013, p. 226)

Nessa mesma corrente de discussão, observa-se que os estudos sobre a educação linguística do professor de línguas no campo da LA se enquadram numa perspectiva, além de linguística, transgressiva, e, no âmbito dessa abordagem, situamos o tópico a seguir.

\section{A LA transgressiva}

No capítulo intitulado "Uma linguística aplicada transgressiva", o qual faz parte da organização de Moita Lopes já referenciada: "Por uma linguística aplicada insdisciplinar", Pennycook acredita na necessidade de antes mesmo de situar a discussão no campo da LA, é preciso esclarecer os quatro conceitos do termo crítico, os quais giram em torno de que se pode ser "crítico no sentido de desenvolver distância crítica e objetividade; crítico no sentido de ser relevante socialmente; crítico seguindo a tradição neomarxista de pesquisa; e crítico como uma prática pós-moderna problematizadora" (2006, p. 67).

A visão de LA na perspectiva transgressiva acrescenta na nomenclatura da disciplina ou campo de estudo os termos 'crítica' e 'contemporânea', ou seja, da forma em que a LA se concretiza como "uma abordagem mutável e dinâmica para as questões da linguagem em contextos múltiplos" (op. cit., p. 67), esta se estabelece como contemporânea, pois vem trazer novos rumos para as discussões e, por consequência, implica nos objetivos de pesquisa em ensino-aprendizagem de línguas, formação de professores e, considerando a repercussão dos estudos dialógicos, nas abordagens sobre gêneros do discurso, responsividade e outras noções referentes a esses estudos.

A LA crítica, contemporânea e transgressiva "é bem mais do que a adição de uma dimensão crítica à LA" tradicional (op. cit, p. 68). Esse avanço da LA trouxe para o campo novos meios de se fazer pesquisa e, da mesma forma, refletir fenômenos sociais que até 
então não eram colocados em pauta no âmbito dos estudos da linguagem, assim como as questões de identidade, sexualidade, ética, raça etc.

Tidas essas considerações, voltamos ao nosso foco de discussão (formação de professores de línguas) apontando a LA transgressiva como forma de trazer novas formas de se inovar a prática de ensino-aprendizagem, uma vez que essa corrente de estudo traz ricos pressupostos teóricos para estimular a competência crítica dos alunos sobre temas diversos como os que aqui foram mencionados.

Nesse contexto, pensar a LA transgressiva direcionada a formação de professores é, além de discutir novos veículos para se ensinar a linguagem em sala de aula, trazer novas formas para se estudar a sociedade pós-moderna e, junto a ela, os mais diversos temas contemporâneos que a cada aula compõem mutuamente a formação humanística dos alunos, a qual identicamente vem sendo responsabilidade da escola, considerando, sobretudo, que necessitamos de "uma LA crítica, e não de uma LA hipócrita, para nos guiar em direção ao futuro" (WIDDOWSON, 2001, p. 16).

Tomadas essas considerações, não sairemos, no tópico seguinte, da questão social que insistimos em mencionar nesse estudo. Sabendo das grandes e ricas inter-relações que os estudos da LA crítica, contemporânea e transgressiva vêm fazendo com os Novos Estudos dos Letramentos, dialogamos sobre as noções de letramento no campo da LA com a formação de professores de línguas.

\subsection{O letramento do professor}

Os Novos Estudos dos Letramentos (NEL) têm como principal aporte teórico os estudos etnográficos de Street $(1984,2014,1984,2006,2013)$, que são primordiais para essa perspectiva de estudo, tanto nos estudos no campo da educação como no da LA. Basicamente, os estudos de Street (1984) esclarecem - por meio da etimologia do termo inglês literacy - que o letramento é caracterizado pelas capacidades de ler e escrever e, nesse contexto, aponta dois modelos de letramento nos quais essas capacidades podem se enquadrar: o modelo autônomo e o modelo ideológico.

O primeiro, modelo autônomo, direciona-se a escola em seu viés tradicional, pois enxerga o letramento como algo estrutural e dicotômico no que concerne a oralidade e a escrita. Constitui, com isso, uma só forma de constituição do letramento, ligada apenas a questões de progresso, civilização e mobilidade social ( $c f$. KLEIMAN, 1995). O modelo ideológico "implica o reconhecimento de fatores que o condicionam por estar (o letramento) estritamente ligado às estruturas culturais e dominantes do meio onde ocorre, isto é, é dependente do jogo de forças nas relações sociais, e considera os contextos de uso" (SANTOS, 2004, p. 120).

A chegada dos estudos de Street no Brasil veio assemelhar a sua teoria com o conceito de alfabetização já tido na educação da época. Nessa perspectiva, o modelo autônomo se direcionava ao conceito de alfabetização, e o ideológico serviu como ponto de partida para a grande abrangência das teorias sobre letramento no país em estudos como os de Soares (1998, p. 107) que apontam o letramento como uma conceituação além 
do que se entende por alfabetização. Assim, para a autora, o sujeito letrado precisa se submeter a um "conjunto de práticas sociais nas quais a escrita tem um papel relevante no processo de interpretação e compreensão dos textos orais ou escritos circulantes na vida social" (KLEIMAN, 2010, p. 337).

A visão de letramento como estado ou condição, fundada por Soares, trouxe uma grande contribuição para os estudos em educação, até porque abrange as duas modalidades de linguagem em uma totalidade para definir 'letramento'. A autora traz a noção do desempenho das práticas de letramento para a formação cidadã dos indivíduos, levando sempre em consideração a formação do aluno no contexto escolar, onde a escola é a principal 'agência de letramento' existente na sociedade. Em se tratando de letramento, Rojo (2009) acredita que para ler, o conhecimento do alfabeto e da decodificação de signos linguísticos não é suficiente, e que é relevante a compreensão (remetendo a compreensão responsiva ativa ${ }^{10}$ ) do que se está lendo, para que o indivíduo possa "prever, hipotetizar, inferir, comparar informações, generalizar. É preciso, conjuntamente, interpretar, criticar, dialogar com o texto: contrapor a ele um ponto de vista, detectando o ponto de vista e a ideologia do autor, situando o texto com seu contexto" (p. 44).

Esse conceito específico abre espaço para uma discussão mais precisa quando o assunto é o ensino e a aprendizagem da língua materna ou de línguas estrangeiras principalmente no que concerne à modalidade oral da linguagem. Nessa linha, a habilidade da leitura se torna mais influente no processo de letramento do que mesmo a escrita. Serve como um ponto de partida. Assim, as capacidades de prever, criar hipóteses, inferir etc. são desenvolvidas na escola, uma vez que é "preciso que a instituição escolar prepare a população para um funcionamento da sociedade [...], de maneira crítica, com diferenças e identidades múltiplas" (ROJO, 2013, p. 7).

É dessa maneira que se torna visível a função importante da unção entre texto e contexto, fazendo com que a escola se apresente como agência e o professor como agente de letramento, pois, como ator social, é levado a criar contextos para que outros atores (os alunos), que se engajarão em atividades relevantes para o grupo, venham a se constituir ( $c f$. KLEIMAN, 2008).

A escola é a principal agência de letramento, porém, devemos ter em mente que a noção de agência não se caracteriza apenas pela estrutura física da escola. A agência, nesse sentido, corresponde "a um espaço sociodiscursivo, no qual há eventos de letramento regidos por práticas letradas construídas socialmente pelos sujeitos participantes das agências" (SILVA, 2009, p. 39). Entende-se, nessa perspectiva, que os agentes de letramento não são os sujeitos participantes dos eventos, os agentes são tidos como facilitadores, isto é, os professores; assim, esse papel se emprega no docente que avalia e atribui conceitos às atividades; "quanto do discente - faça as atividades propostas

\footnotetext{
${ }^{10}$ Qualquer tipo genuíno de compreensão deve ser ativo deve conter já no germe de uma resposta. Só a compreensão ativa nos permite aprender o tema, pois a evolução não pode ser apreendida senão com a ajuda de um outro processo evolutivo. Compreender a enunciação de outrem significa orientar-se em relação a ela, encontrar o seu lugar adequado no contexto correspondente. A cada palavra da enunciação que estamos em processo de compreender, fazemos corresponder uma série de palavras nossas, formando uma réplica (BAKHTIN/VOLOCHÍNIV, 2006, p. 135).
} 
com o intuito de receber boas notas e de, consequentemente, ser aprovado ao final do ano letivo" (op. cit., p. 40).

Sobre as chamadas práticas de letramento, Rojo (2008) aponta que nelas pode-se utilizar um ou mais gênero (s) discursivo (s). Essa noção tornou-se, há alguns anos, difícil de ser compreendida, ou seja, ainda não se tinham conceitos efetivados sobre o que seria a prática e o evento. Diante desse fato e tentando explicá-lo, Lopes (2006, p. 31) assinala que "a distinção entre as noções de evento de letramento e práticas de letramento é utilizada só para efeito metodológico e didático, uma vez que estes componentes representam uma mesma realidade interacional".

Com isso, compreende-se essa distinção através de uma comparação. Se a agência é o espaço sociodiscursivo no qual o evento se realiza, ela se apresenta - ao mesmo tempo - como uma realidade interacional; já que os eventos se distanciam das práticas por questões metodológicas, supõe-se que o papel do evento é, especialmente, servir como uma ferramenta metodológica que estimule o uso da leitura e da escrita ( $c f$. SOARES, 1998) ou somente da escrita ( $c f$. KLEIMAN, 1995) atuam como ponto principal ou ferramenta base. As práticas, então, acontecem perante a metodologia utilizada para a realização do evento.

Nessa perspectiva, o letramento do professor se constitui com base em suas experiências nas práticas escolares, onde o objetivo - do professor e das hierarquias pedagógicas - deve ser contribuir para o letramento dos alunos. Dessa maneira, o letramento do professor está intimamente relacionado à sua formação inicial e continuada, bem como a sua atuação profissional enquanto facilitador do processo de ensinoaprendizagem de línguas. Com isso, o agente de letramento responsável por apontar os caminhos em que a aprendizagem dos sujeitos em processo de aprendizagem deve se situar, é, do mesmo modo, um desses sujeitos-aprendizes.

\section{Considerações finais}

A compreensão dos avanços dados pela LA no cenário científico se enquadra, mesmo com as múltiplas pesquisas realizadas, num panorama complexo de ser estudado, isso porque o surgimento desses estudos é tão emergente a ponto de dificultar o processo de harmonização das noções de LA criadas ao longo desses anos. Nesse sentido, as últimas considerações focalizadas nesse tópico giram em torno das perspectivas explanadas no decorrer do trabalho, na tentativa de retomar alguns conceitos importantes que implicam de forma relevante para futuros estudos referenciando a formação de professores de línguas.

A preocupação em se refletir o papel do linguista aplicado se dá pelas diferentes formas que esses pesquisadores centram-se em seus estudos. Com base nas considerações de Moita Lopes (2006) e Rojo (2006, 2009), observa-se que o primeiro teórico concentra os seus olhares para as questões de identidade, gênero e sexualidade em contextos em que a linguagem tem papel central, já a segunda vem discutir com mais enfoque nas relações dialógicas constituídas por meio das práticas de letramento (oralidade e escrita) em eventos de letramentos escolares. 
As diferentes abordagens teóricas inter-relacionadas no decorrer do estudo com a formação de professores de línguas deixou visível às múltiplas facetadas que podem ser aprofundadas na formação inicial e continuada de professores no intuito de trazer às práticas de ensino-aprendizagem, pressupostos significativos para a formação de alunos cada vez mais críticos e reflexivos. A educação linguística vem remeter a defesa de um ensino pautado na linguagem em sentido macro; a LA transgressiva traz ricas contribuições com os temas basilares para o debate com base no estudo da linguagem em sala de aula; e os estudos sobre letramento do professor surgem como forma de conscientizar a comunidade docente acerca de seus papeis enquanto aprendizes quando exercem o trabalho de facilitadores através das práticas de letramento.

Portanto, vê-se que a LA dispõe de muitas possibilidades de aprimoramento para a prática pedagógica de professores de línguas. Vistos os já referenciados objetivos desse estudo, espera-se, com ele, abrir espaço para outras abordagens bibliográficas e qualitativas mostrando como a heterogeneidade da LA implicou ou pode implicar no ensino de determinada língua, isso, tanto com intervenções realizadas no âmbito da educação básica ou, até mesmo em contexto científico de formação pré-serviço de professores de línguas.

\section{Referências}

BAGNO, M. Nada na língua é por acaso: por uma pedagogia da variação linguística. São Paulo: Editorial, 2007.

BAKHTIN, M. (VOLOCHINOV, V.N.). Marxismo e filosofia da linguagem. $12^{\mathrm{a}}$. ed. São Paulo: Hucitec, 2006.

BORTONI-RICARDO, S.M. Nós chegemu na escola, e agora? Sociolinguística e educação. São Paulo: Parábola Editorial, 2005.

BORTONI-RICARDO, S.M. Educação em língua materna: a sociolinguística na sala de aula. São Paulo: Parábola, 2004.

BRASIL, SNEB. Parâmetros Curriculares Nacionais: Língua Portuguesa. Brasília: MEC, 1998.

CAVALCANTI, M. A propósito de Linguística Aplicada. Trabalhos em Linguística Aplicada, v. 7, 5-12, 1986.

CAVALCANTI, M.C. Educação linguística na formação de professores de línguas: intercompreensão e práticas translíngues. Em: MOITA LOPES, L.P. da. Linguística aplicada na modernidade recente. São Paulo: Parábola Editorial, 2013. p. 211-226.

CRISTOVÃO, L.S.G. Ethos e práticas identitárias: um estudo das imagens de si no discurso de professores de Espanhol Língua Estrangeira. Dissertação. Mestrado em Letras, Faculdade de Letras, Universidade Federal de Rio de Janeiro, 2010. 
DIAS, L.A.X; SANTOS, D.E. Compreensão Responsiva no gênero discursivo Fórum de Discussão. X Seminário de Iniciação Científica SóLetras: Estudos Linguísticos e Literários, [Anais], Jacarezinho, PR, UENP, 2013. p. 162-178.

FABRÍCIO, B. F. Linguística aplicada como espaço de desaprendizagem: redescrições em curso. Em: MOITA LOPES, L.P. da. Por uma linguística aplicada indisciplinar. São Paulo: Parábola, 2006. p. 15-66.

HALL, S. A identidade cultural na pós-modernidade. $7^{\text {a }}$. ed. Trad. Bras. Rio de Janeiro: DP\&A, 2003.

KLEIMAN, A.B. Trajetórias de acesso ao mundo da escrita: relevância das práticas não escolares de letramento para o letramento escolar. PERSPECTIVA, Florianópolis, v. 28, n. 2, 375-400, jul./dez, 2010.

Os estudos de letramento e a formação do professor de língua materna. Linguagem em (Dis)curso, v. 8, n. 3, p. 487-517, set./dez. 2008.

O estatuto disciplinar da linguística aplicada: o traçado de um percurso. In: SIGNORINI, I; CAVALCANTI, M.C. (Orgs.) Um rumo para o debate. Campinas: Mercado das Letras, 1998. p. 51-77.

Modelos de letramento e as práticas de alfabetização na escola. Em: KLEIMAN, A. (Org). Os significados do letramento. Campinas: Mercado de Letras, 1995.

KOCH, I.V; ELIAS, V.M. Ler e escrever: estratégias de produção textual. São Paulo: Editora Contexto, 2011.

LOPES, I.A. Cenas de Letramentos Sociais. Programa de Pós Graduação em Letras, UFPE, Recife, 2006.

MAINGUENEAU, D. A propósito do ethos. Em: MOTTA, A.R.; SALGADO, L. (Orgs.). Ethos discursivo. São Paulo: Contexto, 2008.

MOITA LOPES, L.P. da (Org.). Linguística Aplicada na modernidade recente. São Paulo: Parábola, 2013.

Por uma linguística aplicada indisciplinar. São Paulo: Parábola, 2006.

PENNYCOOK, A. Uma linguística aplicada transgressiva. Em: MOITA LOPES, L.P. da. Por uma linguística aplicada indisciplinar. São Paulo: Parábola, 2006. p. 67-84.

RAJAGOPALAN, K. Repensar o papel da linguística aplicada. Em: MOITA LOPES, L.P. da (Org.). Por uma linguística aplicada indisciplinar. São Paulo: Parábola, 2006. p. 149-168.

ROJO, R. (Org.). Escola conectada: os multiletramentos e as TICs. São Paulo: Parábola, 2013. 
Letramentos múltiplos, escola e inclusão social. São Paulo: Parábola, 2009.

Fazer linguística aplicada em perspectiva sócio-histórica: entre a privação sofrida e a leveza de pensamento. Em: MOITA LOPES, L.P. da. Por uma linguística aplicada indisciplinar. São Paulo: Parábola, 2006. p. 253-275.

SANTOS, J.S. Letramento, variação lingüística e ensino de português. Linguagem em (Dis)curso, Tubarão, v. 5, n.1, p. 119-134, jul./dez. 2004.

SILVA, E. M. Histórico de letramento e práticas letradas em redações de vestibular. Dissertação. Mestrado em Linguagem e Ensino, Programa de Pós-Graduação em Linguagem e Ensino, Universidade Federal de Campina Grande, 2009.

SCAFUTTO, M.L; CYRANKA, L.F.M. Educação Linguística: para além da língua padrão. Educação em Foco, Juiz de Fora, v. 16, p. 41-64, 2011.

SILVA JÚNIOR, S. N. A importância da concepção dialógica de linguagem na formação do professor de língua materna: a análise da compreensão responsiva ativa em sala de aula. Em: SILVA JÚNIOR, S.N; SILVA, E.B. (Re)pensando a pesquisa em linguagem: várias questões, múltiplos olhares. Pará de Minas, MG: Virtual Books, 2017. p. 8-27.

Contribuições da literatura para a formação de professores de língua materna: refletindo a narrativa autobiográfica. Monografia. Especialização em Língua Portuguesa e Literatura Brasileira), Instituto Prominas, Universidade Cândido Mendes, 2016b.

. Narrativas autobiográficas: a tessitura das identidades de professores de língua materna - um olhar interpretativista. Monografia. Graduação em Letras: Língua Portuguesa, Departamento de Letras, Universidade Estadual de Alagoas, 2016a.

SOARES, M. Letramento: um tema em três gêneros. Belo Horizonte: Autêntica, 1998.

SOUTO MAIOR, R.C. As constituições de Ethos e os Discursos Envolventes no Ensino de Língua Portuguesa em Contexto de Pesquisa-ação. Tese. Doutorado em Linguística. Faculdade de Letras, Universidade Federal de Alagoas, 2009.

STREET, B.V. Letramentos sociais: abordagens críticas do letramento no desenvolvimento, na etnografia e na educação. Trad. Bras. São Paulo: Parábola, 2014.

Políticas e práticas de letramento na Inglaterra: uma perspectiva de letramentos sociais como base para uma comparação com o Brasil. Cad. CEDES, v. 33, n. 89, Campinas, jan. - abr., 2013.

STREET, B. V. Perspectivas interculturais sobre o letramento. Trad. Bras. Filologia linguística do português, n. 8, p. 465-488, 2006.

Literacy in theory and practice. Cambridge: CUP, 1984.

THIOLlENT, M. Metodologia da pesquisa-ação. São Paulo: Cortez; Autores Associados, 1988. 
VASCONCELOS, M.L.M.C. A educação linguística e a formação de professores. Cadernos de Letras, UFF, Dossiê: Diálogos Interamericanos, n. 38, p. 205-215, 2009.

VIAN JR, O. A educação linguística do professor de inglês. Em: SZUNDY, P.T.C et al. Linguística aplicada e sociedade: ensino e aprendizagem de línguas no contexto brasileiro. Campinas: Pontes, 2011. p. 61-75.

WIDDOWSON, H.G. Coming to Terms With Reality: Applied Linguistics in Perspective. In: GRADDOL, D. (Org.) Applied Linguistics for the $21^{\circ}$ Century. AILA Review, v. 14, 2001. p. 2-17.

ZOZZOLI, R.M.D. Produção e autonomia relativa na aprendizagem de línguas. Em: LEFFA, V.J. Pesquisa em Linguística Aplicada: temas e métodos. Pelotas: Educat, 2006. p. $99-138$.

Artigo recebido em: maio de 2017.

Aprovado e revisado em: setembro de 2017.

Publicado em: novembro de 2017.

\section{Para citar este texto:}

SILVA JÚNIOR, Silvio Nunes da. Linguística Aplicada e formação de professores de línguas: conceitos e tramitações. Entremeios [Revista de Estudos do Discurso, on-line, www.entremeios.inf.br], Seção Estudos, Programa de Pós-Graduação em Ciências da Linguagem (PPGCL), Universidade do Vale do Sapucaí (UNIVÁS), Pouso Alegre (MG), vol. 15, p. 31-46, jul. - dez. 2017.

DOI: http://dx.doi.org/10.20337/ISSN2179-3514revistaENTREMEIOSvol15pagina31a46 